\title{
Inspirational Women in Surgery: Dr Claire Karekezi, Neurosurgeon, Rwanda
}

\author{
Kathryn $\mathrm{Chu}^{1}$
}

Accepted: 4 February 2022/Published online: 5 March 2022

(C) The Author(s) under exclusive licence to Société Internationale de Chirurgie 2022

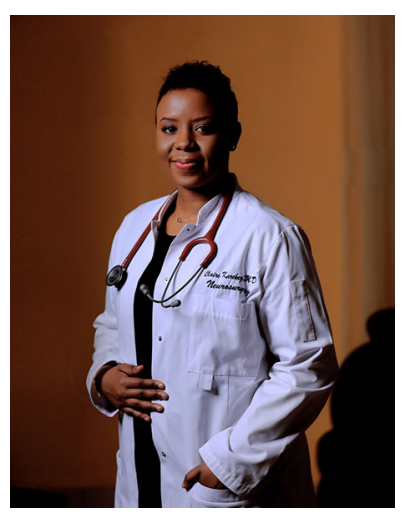

Sub-Saharan Africa (SSA) has a dire shortage of neurosurgeons with fewer than 1 per 6 million persons [1]. Rwanda is a landlocked country in East-Central Africa with an estimated population of 13 million. The country has been deeply affected by the 1994 genocide that left at least 1 million people dead. The health sector was also decimated with the majority of the health professionals killed and most of the health system itself, including infrastructure and equipment, destroyed.

Since then, Rwanda has been steadily re-building its healthcare workforce, but surgical training programs are only in their infancy. The University of Rwanda (formerly National University of Rwanda) restarted its medical school in 1996 and created its first general surgery training program in 2005. Before this time, surgeons and other specialists were trained outside of Rwanda, mainly in South Africa, West Africa, East Africa and Europe [2].

Kathryn Chu

kchu@sun.ac.za

1 Centre for Global Surgery, Stellenbosch University Faculty of Medicine and Health Sciences, Cape Town, South Africa
When Dr. Claire Karekezi started medical school in 2002, neurosurgery did not exist in Rwanda. Neurology and neurosurgery were taught in the classroom, but there was no formal neurosurgery training and not a single practicing Rwandan neurosurgeon in the country. The scarce neurosurgical care was provided by expatriate surgeons from South Africa and Cuba. Today Dr. Karekezi is the first and only female neurosurgeon in Rwanda and running a neurosurgery unit at the Rwanda Military Hospital (RMH), one on the country's largest tertiary referral hospitals. She has been a true pioneer in her field, and her story is one of grit, determination and collaboration.

As a senior medical student, Dr. Karekezi was inspired to study abroad and learn about medicine in higher resourced countries. By chance, she selected a neurosurgery rotation at the Linköping University Hospital in Sweden under the tutelage of Dr. Jan Hillman, the Department Chair of Neurosurgery. After seeing her first craniotomy, she became fascinated by the brain and its pathologies. She decided to become a neurosurgeon and began teaching herself the basics of neuroanatomy. Without an established training program in Rwanda, Dr. Karekezi forged her own path outside her home country. After her Swedish rotation, she secured sponsorship for an elective rotation at Radcliffe Hospital at the University of Oxford where she discovered an organization called the World Federation of Neurosurgical Societies (WFNS). In 2002, the WFNS created the Rabat Reference Center for the Training of Young African Neurosurgeons in Rabat, Morocco. After 3 years of persistence, emailing the program Chair, Dr. Karekezi secured a residency position at the Rabat Center, funded through the Rwandan Ministry of Health, and completed her neurosurgery training between 2011 and 2016. 
Since then, she has furthered her training by completing a visiting fellowship in Neuro-Oncology at the Brigham and Women's Hospital and a clinical Fellowship in NeuroOncology and Skull Base Surgery at the University of Toronto, Toronto Western Hospital, in Canada before returning to Rwanda in August of 2018 to become the country's first female neurosurgeon.

Establishing a neurosurgery practice in the Rwandan public health sector has not been without challenges. She opened her practice at RMH in January 2019, but spent the first several months of her tenure creating a functional neurosurgical unit, locating appropriate surgical instrumentation and staff. Even the most lifesaving operations were difficult to start up; for example, traumatic brain injury patients with compressing epidural or chronic subdural hematomas who needed a small craniotomy or a simple burr hole procedure would come to the unit, but initially there was no appropriate instrumentation nor an adequate neurosurgical critical care unit. In addition to this, there was a lack of crucial surgical equipment to treat brain tumors such as a neurosurgical microscope, endoscopic instrumentation, or adjuvant therapy such radiation therapy and/or chemotherapy services.

After Dr. Karekezi began her training at Rabat, a special collaborative, the Rwanda Human Resources for Health (HRH) Program, was initiated in 2012 that led to the initiation of several residency programs including neurological surgery at the University of Rwanda (UR) [3]. Currently, there are 6 Rwandan neurosurgeons: 3 trained locally by the UR program and 3 (including Karekezi) trained outside of the country. Dr. Karekezi heads up the RMH site for both UR and the College of Surgeons of East, Central and Southern Africa (COSECSA) Neurosurgery training program where the residents rotate every 3 months to learn about the fundamentals of neurosurgery and brain tumor surgery principles.

Neurosurgery remains a male dominated field, especially in Africa. Dr. Karekezi is determined to improve the support and mentorship of her female colleagues. In 2019, she was elected as the chair of the African Women in
Neurosurgery (AWIN) section of the Continental Association of African Neurosurgical Societies (CAANS). In 2021, she authored and led a publication that provides an overview of the history of women in neurosurgery and their current status on the African continent. Even though a lot had been achieved, the study found that the paucity of women neurosurgeons, especially in the SSA region, persists and that women neurosurgeons are still underrepresented in leadership positions and academic neurosurgery. They emphasized the need for more experienced female neurosurgeons to help other young women to overcome different challenges in the demanding specialty [4].

For other African women who may be interested in following in her footsteps, she emphasizes that there are no easy wins; each step comes with its own challenges to tackle and to take advantage of the female surgeon mentors now in practice. She emphasizes that the future is bright for those with the patience, work ethic and perseverance it takes to succeed.

\section{References}

1. Punchak M, Mukhopadhyay S, Sachdev S et al (2018) Neurosurgical care: availability and access in low-income and middleincome countries. World Neurosurg 112:e240-e254. https://doi. org/10.1016/j.wneu.2018.01.029

2. Rickard J, Ssebuufu R, Kyamanywa P, Ntakiyiruta G (2016) Scaling up a surgical residency program in Rwanda. East Cent Afr J Surg 21(1):11-23

3. Delisle H (2018) The human resources for health program in Rwanda - reflections on achievements and challenges comment on "health professional training and capacity strengthening through international academic partnerships: the first five years of the human resources for. Int J Heal policy Manag 8:128-131

4. Karekezi C, Thango N, Aliu-Ibrahim SA et al (2021) History of African women in neurosurgery. Neurosurg Focus 50(3):E15. https://doi.org/10.3171/2020.12.FOCUS20905

Publisher's Note Springer Nature remains neutral with regard to jurisdictional claims in published maps and institutional affiliations. 